\title{
Anatomical Patterns of the Pancreatic Ductal System - A Cadaveric and Magnetic Resonance Cholangiopancreatography Study
}

\author{
${ }^{1}$ Department of Anatomy, Christian Medical College, Vellore, \\ Tamil Nadu, India \\ 2 Department of Radiology, Christian Medical College, Vellore, \\ Tamil Nadu, India \\ ${ }^{3}$ Department of Gastroenterology, Christian Medical College, \\ Vellore, Tamil Nadu, India \\ ${ }^{4}$ Department of Biostatistics, Christian Medical College, \\ Vellore, Tamil Nadu, India
}

Mythraeyee Prasad ${ }^{1}$ Sipra Rout ${ }^{1}$ Tharani Putta ${ }^{2}$ Reuben Thomas Kurien ${ }^{3}$

Sudipta Dhar Chowdhury ${ }^{3}$ Anu Eapen ${ }^{2} \quad$ Y. S. Hepsy ${ }^{4}$ Suganthy Rabi ${ }^{1}$

J Morphol Sci 2019;36:279-285.

\begin{abstract}
Address for correspondence Sipra Rout, MD, DNB, Department of Anatomy, Christian Medical College, Vellore, Tamil Nadu, 632 002, India (e-mail: siprarout@gmail.com).
\end{abstract}

\begin{abstract}
Keywords

- pancreas

- pancreatic ductal pattern

- ansa pancreatica

- pancreas divisum

- magnetic resonance cholangiopancreatography

Introduction Morphological variants of the pancreatobiliary system can predispose to chronic pancreatitis. The goal of the present study is to assess the prevalence of pancreatic duct patterns in the Indian population, both by cadaveric dissection and by magnetic resonance cholangiopancreatography (MRCP).

Materials and Methods A total of 15 adult pancreas specimens of unknown age and gender, and 5 fetal pancreas specimens of different gestational ages with the intact second part of duodenum, were dissected by the piecemeal method. For clinical relevance, MRCP images of 103 clinically-diagnosed chronic pancreatitis patients irrespective of their etiology were obtained retrospectively from the existing database and studied. The anatomical patterns were classified as five different types based on the course of the main pancreatic duct and the accessory pancreatic duct and their openings into the duodenal wall, including variants like pancreas divisum and ansa pancreatica.

Results In the cadaveric study, the main pancreatic duct was single with a straight course in $46.67 \%$ of the adult specimens, and in the MRCP study, the main pancreatic duct showed a descending course in $77.66 \%$ of the cases. The most common pattern was type III in both the cadaveric (80\%) and radiological (55.33\%) studies, and the accessory duct was absent on the MRCP in all type-III cases, while it ended blindly in the cadaveric specimens. Ansa pancreatica (type $\mathrm{V}$ ) was observed in 1 adult specimen (6.7\%), but not in the radiological study. Pancreas divisum (type IV) was observed in the 8 cases $(7.76 \%)$ cases in the radiological study.

Conclusion Knowledge of the anatomical variants of the pancreatic ductal system may be helpful for the radiologists during diagnostic and therapeutic interventional procedures.
\end{abstract}

received July 4, 2019 accepted July 20, 2019
DOI https://doi.org/

10.1055/s-0039-1698371. ISSN 2177-0298.
Copyright $(2019$ by Thieme Revinter

Publicações Ltda, Rio de Janeiro, Brazil
License terms

c) $\oplus \triangleq \$$ 


\section{Introduction}

Pancreatitis has been described as a serious and often fatal disease. It can present in acute or chronic form. There are several causes for chronic pancreatitis. Morphological anomalies of the pancreatobiliary system have been described as one of the predisposing factors for chronic pancreatitis. ${ }^{1}$ Dawson and Langman ${ }^{2}$ studied the anatomical patterns of the pancreatic ductal system in adults by dissection, and classified them into four groups: embryonic type, patent accessory duct, ansa pancreatica and obliterated accessory duct. The anatomical variations of the accessory pancreatic duct (APD) were studied by dissection in terms of its shape, course, opening into the duodenum, patency and communication with the main pancreatic duct (MPD). ${ }^{3,4}$ Sunjida Shahriah et $\mathrm{al}^{3}$ studied in detail the course of the APD (describing it as straight, spindle and cudgel) and its communication with the MPD radiologically using Barium X-ray.

The importance of the anatomical variants of the pancreatic ductal system and anomalous pancreatobiliary union was described radiologically using endoscopic retrograde cholangiopancreatography (ERCP). ${ }^{5}$ Magnetic resonance cholangiopancreatography (MRCP) was described as a better method of visualizing the pancreatic and biliary ductal anatomy compared with the ERCP, since it is non-invasive and safer. ${ }^{6,7}$ However, the literature on the aforementioned anatomical patterns of the pancreatic ductal system and its variants by cadaveric dissection substantiated along with radiological studies using MRCP is not available for the Indian population. Our aim is to study the prevalence of the pancreatic duct patterns in the Indian population by cadaveric dissection and by MRCP.

\section{Materials and Methods}

Ethical clearance from the Institutional Review Board was obtained.

\section{Cadaveric Study}

A total of 15 adult pancreas and 5 fetal pancreas specimens of different gestational ages ( 26 to 38 weeks) were obtained from cadavers donated to the Department of Anatomy of our institution for the purpose of teaching and research; they were dissected by the piecemeal method. The pancreatic ductal system was colored with acrylic paint for better visualization.

In the adults, the presence or absence of the major and minor duodenal papillae was studied. The number of pancreatic ducts, the length of the MPD, and its opening into the duodenal wall in human adult pancreas specimens were studied. The presence or absence of an APD, its pattern and communication with the MPD, and its opening into the duodenal wall in human adult pancreas were noted. The course of the MPD was classified as descending, sigmoid, vertical and loop, as described by Türkvatan et al. ${ }^{8}$ The anatomical patterns of the pancreatic ductal system were classified into six different types based on the course of the MPD and APD and their openings into the duodenal wall ${ }^{8}$ (-Fig. 1). The length of the MPD was measured using a

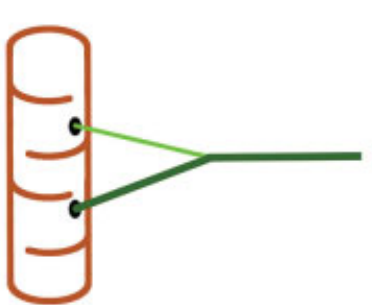

Type I

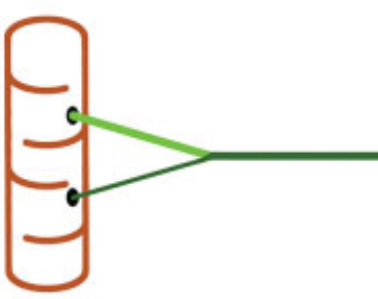

Type II

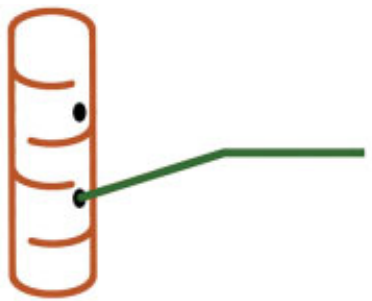

Type III

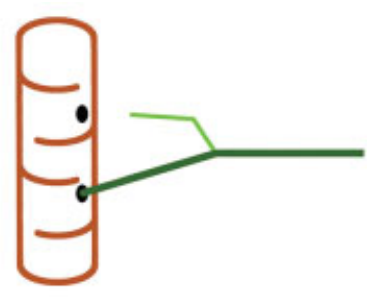

Type III

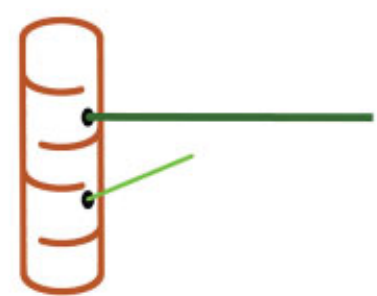

Type IV

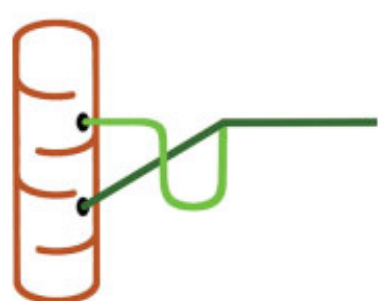

Type V

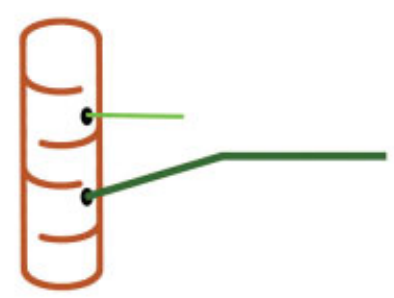

Type VI

Fig. 1 Schematic diagram showing the different anatomical patterns of the pancreatic ductal system. Type I - the dominant duct of drainage is the main pancreatic duct, which opens into the major duodenal papilla, and has an accessory duct communicating with it, which opens into the minor duodenal papilla; type II - the dominant duct of drainage is the accessory pancreatic duct, which opens into the minor duodenal papilla and communicates with the main pancreatic duct, which opens into the major duodenal papilla; type III - main pancreatic duct with absent/blind accessory duct; type IV - pancreas divisum; type V - ansa pancreatica; type VI- the accessory duct opens into the minor duodenal papilla and has no communication with the main pancreatic duct. 
Table 1 Pancreatic ducts of the fetal pancreas specimens

\begin{tabular}{|l|l|l|l|l|l|}
\hline $\begin{array}{l}\text { Foot } \\
\text { length } \\
(\mathbf{m m})\end{array}$ & $\begin{array}{l}\text { GA/ } \\
\text { Gender }\end{array}$ & $\begin{array}{l}\text { Major } \\
\text { duodenal } \\
\text { papilla }\end{array}$ & $\begin{array}{l}\text { Minor } \\
\text { duodenal } \\
\text { papilla }\end{array}$ & MPD & APD \\
\hline 55 & $26 / \mathrm{F}$ & + & - & + & - \\
\hline 66 & $30 / \mathrm{F}$ & + & - & + & - \\
\hline 70 & $32 / \mathrm{F}$ & + & - & + & - \\
\hline 78 & $36 / \mathrm{F}$ & + & + & + & - \\
\hline 80 & $38 / \mathrm{F}$ & + & + & + & - \\
\hline
\end{tabular}

Abbreviations: APD, accessory pancreatic duct; F, female; GA, gestational age; MPD, main pancreatic duct; $+/-$, present/absent.

Table 2 Course of the main pancreatic duct

\begin{tabular}{|l|l|l|}
\hline Variables & $\begin{array}{l}\text { Cadaveric study } \\
(\boldsymbol{n}=\mathbf{1 5})\end{array}$ & $\begin{array}{l}\text { MRCP study } \\
(\boldsymbol{n}=103)\end{array}$ \\
\hline Descending & $6(40 \%)$ & $80(77.66 \%)$ \\
\hline Vertical & 0 & $10(9.70 \%)$ \\
\hline Sigmoid & $2(13.3 \%)$ & $13(12.62 \%)$ \\
\hline Loop & 0 & 0 \\
\hline Straight & $7(46.67 \%)$ & 0 \\
\hline
\end{tabular}

Abbreviation: MRCP, magnetic resonance cholangiopancreatography.

measuring tape. The associated variations of the pancreatic ductal system, like pancreas divisum and ansa pancreatica, were examined. The pattern of pancreatobiliary union and its opening into the duodenal wall was studied. The length of the common channel, if the union of the common bile duct and the MPD was extraduodenal, was measured.

For the fetal study, the foot length in millimeters was considered as the reference for the interpretation of the gestational age in weeks. ${ }^{9}$ The presence or absence of the MPD, the APD, the common bile duct, and the major and minor duodenal papillae were studied.

\section{Radiological Study}

For clinical relevance, the same parameters (number and course of the MPD, presence or absence of an APD, and its communication with the MPD and minor duodenal papilla) were studied radiologically using MRCP images. Images of clinically-diagnosed chronic pancreatitis patients, irrespective of their etiology, who underwent MRCP, were obtained retrospectively from the existing database. Patients with
Table 3 Types pancreatic ductal system

\begin{tabular}{|l|l|l|}
\hline Types & Cadaveric study $(\boldsymbol{n}=15)$ & MRCP study $(\boldsymbol{n}=\mathbf{1 0 3})$ \\
\hline I & $2(13.3 \%)$ & $26(25.24 \%)$ \\
\hline II & 0 & $4(3.88 \%)$ \\
\hline III & $12(80 \%)$ & $57(55.33 \%)$ \\
\hline IV & 0 & $8(7.76 \%)$ \\
\hline V & $1(6.7 \%)$ & 0 \\
\hline VI & 0 & $8(7.76 \%)$ \\
\hline
\end{tabular}

Abbreviation: MRCP, magnetic resonance cholangiopancreatography.

suboptimal imaging and those with any previous history of pancreatobiliary surgery were excluded from the study. A total of 103 consecutive patients (67 male and 36 female patients) were selected and included in the study. The mean age of the patients was 37 years (range: 9-87 years).

The data was statistically analyzed.

\section{Results}

\section{Cadaveric Study}

In all of the five fetal pancreas specimens, a single MPD was present, which opened into the major duodenal papilla. As the gestational age increased, the minor duodenal papilla was identified. The APD was not observed in any of the five specimens (-Table $\mathbf{1}$ ).

In the adults, the major duodenal papilla was present in all of the 15 specimens. The minor duodenal papilla was present in 11 (73.3\%) specimens. The MPD was single, and had a straight course in $46.7 \%$ (7) of the specimens, followed by the descending course in $40 \%$ (6), and the sigmoid course in $13.3 \%$ (2) of the specimens. There were no specimens with vertical and loop

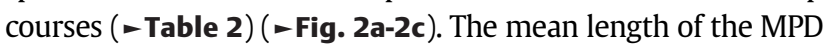
was $16.17 \pm 1.57 \mathrm{~cm}$. The APD was present in 10 (66.67\%) specimens, and it was blind, disappearing within the substance of the head of the pancreas and not opening into the duodenal wall.

- Table 3 shows that the most common ductal pattern observed in the cadaveric pancreases was of type III, in which the APD was blind $(\mathrm{n}=12 ; 80 \%)$. Ansa pancreatica was observed in $1(6.66 \%)$ specimen (-Fig. 3a-3c).

i. The MPD continues as the duct of Wirsung, which is the dominant duct of drainage, and opens into the major duodenal papilla; the APD communicates with the MPD

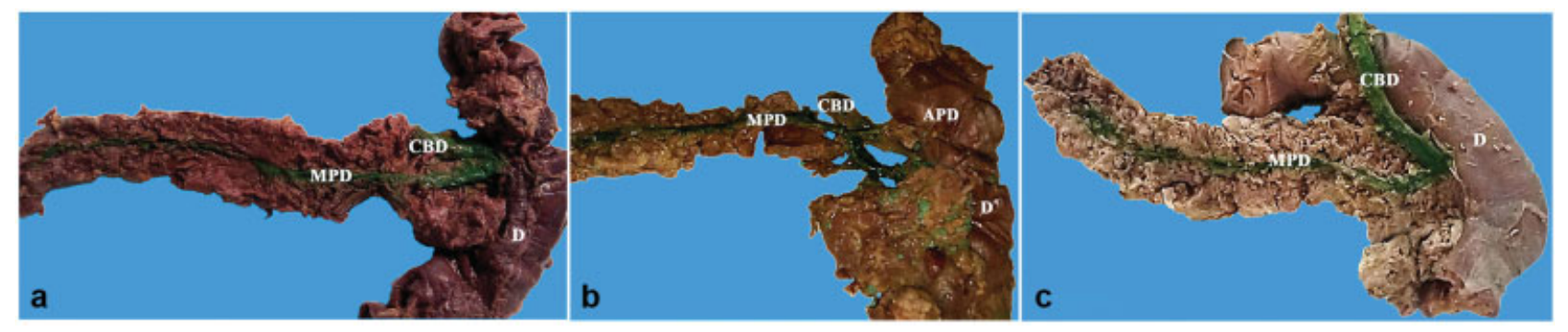

Fig. 2 Course of the main pancreatic duct in the cadaveric study. (a) Straight; (b) descending; and (c) sigmoid. Abbreviations: D, duodenum; MPD, main pancreatic duct; APD, accessory pancreatic duct; CBD, common bile duct. 

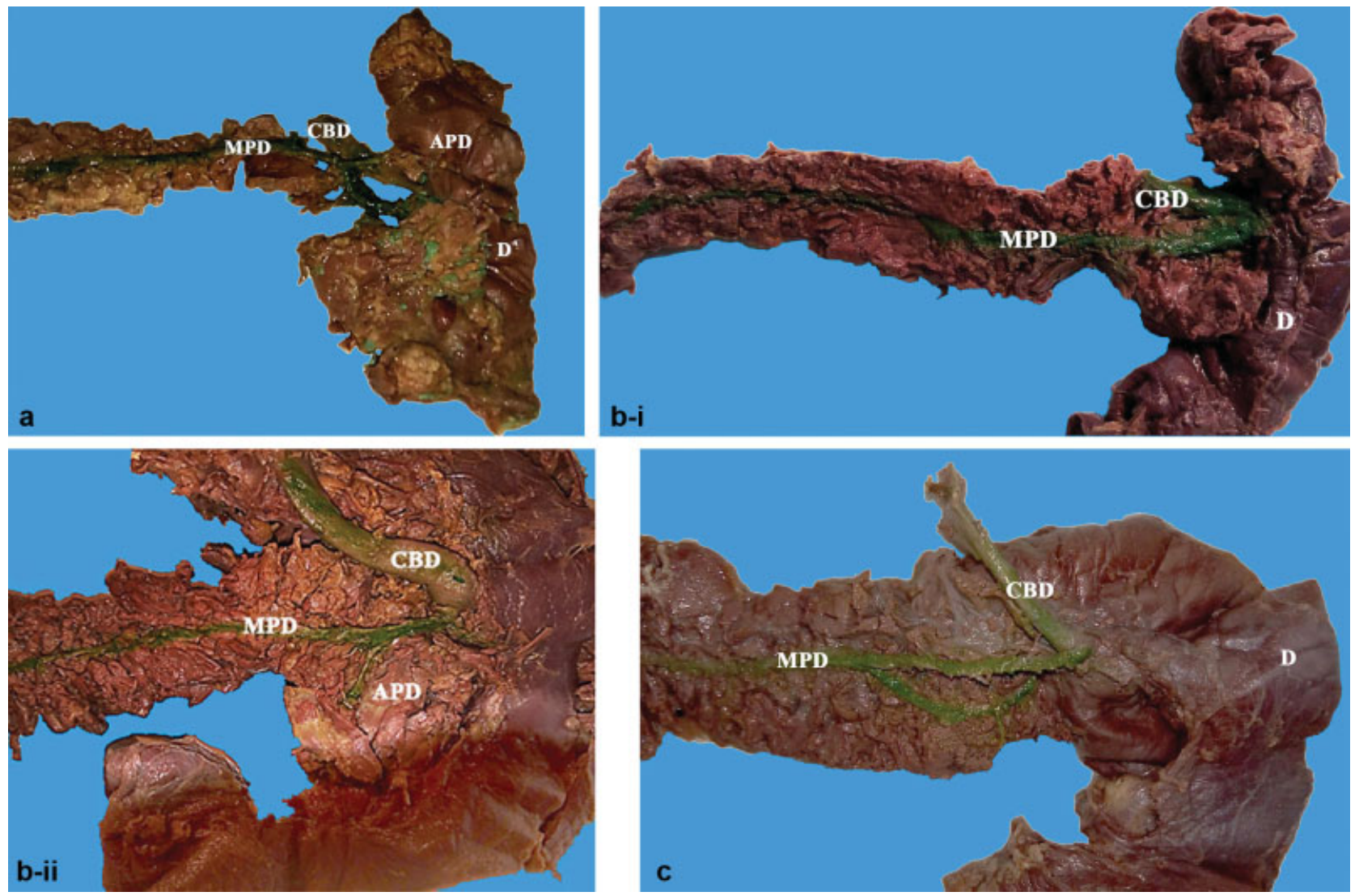

Fig. 3 Types of pancreatic ductal system in the cadaveric study. (a) Type I- Dominant duct of drainage is Main pancreatic duct opening into the major duodenal papilla and has accessory duct communicating with it and opening into the minor duodenal papilla; (b-i) Type III (Main pancreatic duct with absent accessory duct), (b-ii) Type III (Main pancreatic duct with blind Accessory duct draining uncinate process);

(c) Type V (Ansa pancreatica).

and opens into the duodenal wall at the minor duodenal papilla (-Fig. 1)

ii. The MPD continues to drain into the minor duodenal papilla through the dominant accessory duct or duct of Santorini; the duct of Wirsung maintains communication with the dorsal duct ( - Fig. 1)

iii. The APD is absent/blind (-Fig. 1)

iv. Pancreas divisum: the MPD and APD open into the minor and major duodenal papillae, and there is no communication between them in the classic subtype of pancreas divisum (-Fig. 1)

v. Ansa pancreatica: the APD is obliterated at its junction with the ventral duct, and is replaced with an additional curved communicating duct between the ventral and dorsal ducts at the pancreatic head. (-Fig. $\mathbf{1}$ )

vi. The MPD opens into the major duodenal papilla, and the APD opens into the minor duodenal papilla, but there is no communication between them ( $\boldsymbol{-}$ Fig. 1).

The pancreatobiliary union occurred mostly in the duodenal wall ( $\mathrm{n}=13 ; 86.67 \%)$, and it was extra-duodenal in 2 (13.32\%) cases. The mean length was $5 \mathrm{~mm}$.

\section{Radiological Study}

The APD was observed in all of the 103 MRCP images (100\%), and the APD was present in 45 (43.26\%) of them.
The predominant course of the MPD was descending, followed by the sigmoid and vertical courses (-Table 2 ) (-Fig. 4a-4c). There was no loop course. The APD was absent in 57 cases $(55.33 \%)$

Similar to the cadaveric study, the most common duct type observed was type III (-Figs. 5c). The three subtypes of pancreas divisum (type IV) were noted ( - Figs. 5d-i,ii,iii). Ansa pancreatica (type V) was not observed in the present MRCP study. We have identified another subtype not described by Türkvatan et $\mathrm{al}^{8}{ }^{8}$ in which the APD opens into the duodenal wall and ends blindly in the substance of the pancreatic head without communicating with the MPD, and this has been categorized as type VI in 8 cases (7.76\%). There was no gender difference regarding the course of the MPD (Chi-squared $\left[\mathrm{X}^{2}\right]=4.97 ; p=0.083$ ) and the types of pancreatic ductal system $\left(X^{2}=8.93\right.$; $p=0.06$ ).

\section{Discussion}

The pancreas is drained by the MPD (duct of Wirsung), which opens into the major duodenal papilla in the second part of duodenum. It is usually formed from the distal part of the duct of the dorsal pancreatic bud and the entire duct of the ventral pancreatic bud. The APD (duct of Santorini) is formed from the proximal part of the duct of the dorsal pancreatic bud till its 

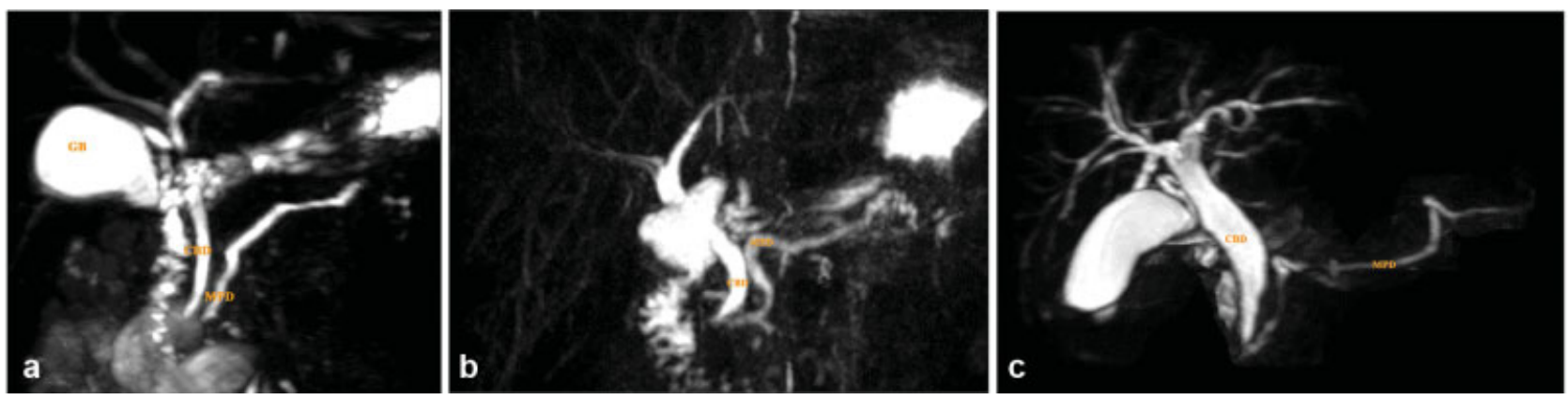

Fig. 4 Course of the main pancreatic duct in the radiological study. (a) Descending; (b) sigmoid; and (c) vertical. Abbreviations: MPD, main pancreatic duct; CBD, common bile duct, GB, gall bladder.
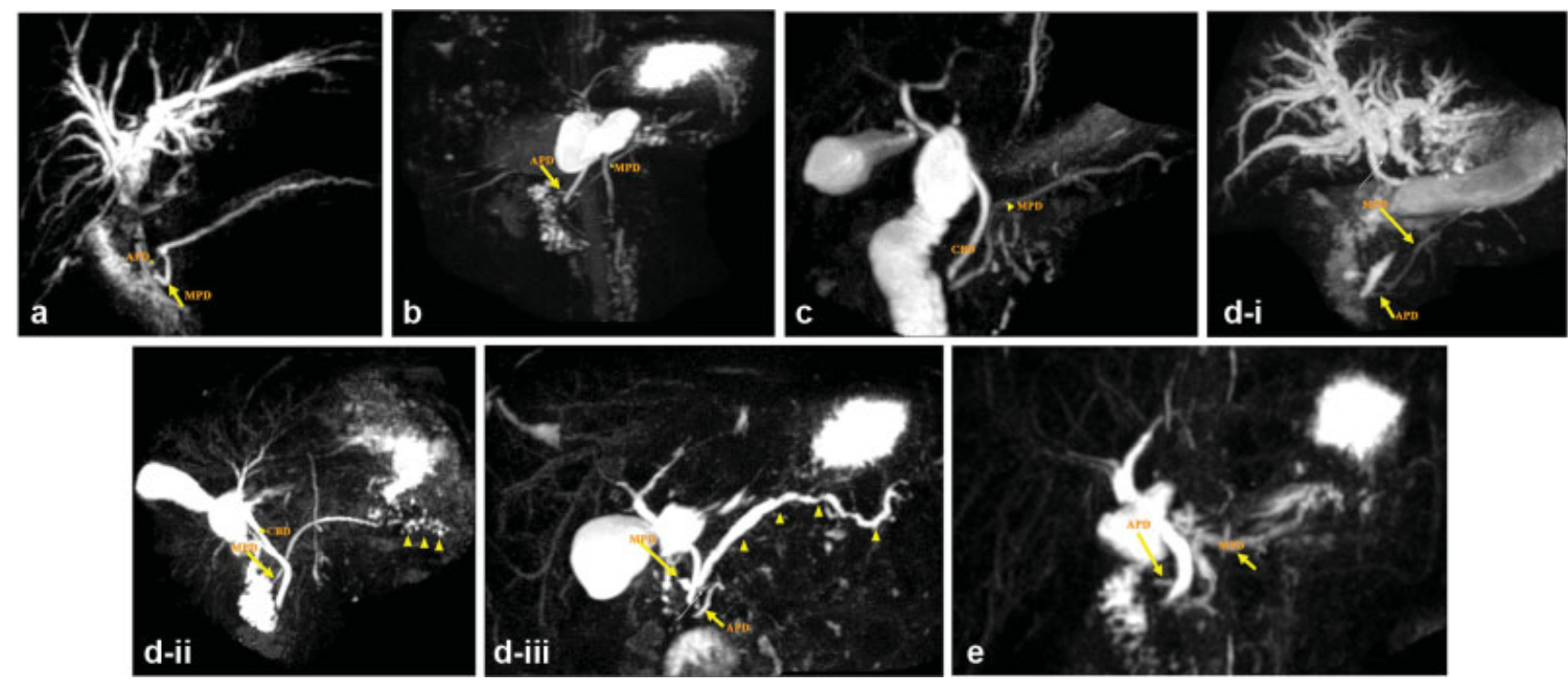

Fig. 5 Types of pancreatic ductal system in the radiological study. (a) Type I-bifid configuration with dominant duct of Wirsung (arrow); (b) type II - bifid configuration with dominant duct of Santorini (arrow) without divisum; (c) type III - absent duct of Santorini; (d-i) type IV (subtype I): classic pancreas divisum in which there is complete failure of fusion of the dorsal duct (long yellow arrow) and the ventral duct (short yellow arrow); (d-ii) type IV (subtype II): main pancreatic duct draining into the minor papilla (long yellow arrow), and the duct of Wirsung is absent. The distal pancreatic duct in the tail is beaded with dilated side branches (arrow heads), which is suggestive of chronic pancreatitis; (d-iii) type IV (subtype III): the main pancreatic duct drains into the minor papilla (long yellow arrow). The ventral duct of Wirsung (short yellow arrow) is seen communicating with the dorsal duct through a filamentous communication (thin white arrow). The pancreatic duct is irregularly dilated (arrow heads) in this patient with chronic pancreatitis; (e) type VI - duct of Santorini (long arrow) communicating with the minor duodenal papilla but not with the main pancreatic duct (short arrow).

opening into the second part of duodenum at the minor duodenal papilla. ${ }^{10}$

Morphological anomalies of the pancreatobiliary system have been described as one of the predisposing factors for chronic pancreatitis. Variants of the pancreatic ductal system like pancreas divisum and ansa pancreatica are mostly incidental findings during various radiologic procedures, like the ERCP, since the patient might be asymptomatic. Knowledge about these anatomical patterns of the pancreatic ductal system and its variants are radiologically important because these might lead to post-ERCP pancreatitis due to the ductal injury caused during the procedure. ${ }^{1}$

There are a few studies available on the anatomical patterns of the pancreatic ductal system performed on different populations. Dawson and Langman ${ }^{2}$ reported that the MPD was present in all of the specimens in their study on 120 adult pancreas specimens, and Adibelli et $\mathrm{al}^{7}$ reported the same in their MRCP study of 1,158 chronic pancreatitis patients. The findings were similar in the present study. While the course of the MPD was straight in our cadaveric study, the MRCP study revealed that the descending course was the most common, followed by the sigmoid and vertical courses, which is in accordance with the studies by Türkvatan et $\mathrm{al}^{8}{ }^{8}$ Adibelli et $\mathrm{al}^{7}{ }^{7}$ and Shu et al. ${ }^{11}$ The presence of the loop course in the previous studies and its absence in the present study may indicate that ethnical factors play a role in the prevalence of different courses of the MPD. In the present study, the mean length of the MPD was $16.17 \pm 1.57 \mathrm{~cm}$, which is similar to the mean of $16.13 \pm 3.26 \mathrm{~cm}$ reported by Ara et al. ${ }^{12}$ Govindraj and Shabna ${ }^{13}$ reported a mean length of the MPD of $11.1 \mathrm{~cm}$ in the Indian population, a value lower than that of the present study. Other studies on the mean length of the MPD found the following values: Kang et al: ${ }^{14} 17.5 \pm 2.8 \mathrm{~cm}$; Kochhar et $\mathrm{al}^{:{ }^{15}} 18.2 \pm 3 \mathrm{~cm}$; and Sahni et al: ${ }^{16} 17.1 \pm 1.59 \mathrm{~cm}$ in males, and $15.1 \pm 1.38 \mathrm{~cm}$ in females. 
Türkvatan et $\mathrm{al}^{8}$ classified the pancreatic ductal system into five types, and reported that the most common type was the MPD (type I) followed by the absent APD (type III). In the present study, type III was the predominant type, which is similar to the studies by Dawson and Langman, ${ }^{2}$ Sunjida Shahriah et al, ${ }^{3}$ Adibelli et al, ${ }^{7}$ and Bülow et al. ${ }^{17}$ In a literature review on the main anatomical variations of the pancreatic duct system by Dimitriou et al, ${ }^{18}$ a total of 8,260 patients were analyzed. In their study, $94.3 \%$ of the cases displayed normal anatomy (types I-III), $4.5 \%$ had pancreas divisum, and $1.2 \%$ were reported as having rare anomalies. Sunjida Shahriah et $\mathrm{al}^{3}$ reported that type III was the most common type (72.3\%) observed, as well as Adibelli et al, ${ }^{7}$ and Bülow et al, ${ }^{17}$ who reported prevalences of $63 \%$ and $45.6 \%$ respectively.

Pancreas divisum (type IV) is a common congenital pancreatic anomaly in which the dorsal and the ventral pancreatic buds fail to fuse. It is implicated as a cause for idiopathic chronic pancreatitis. ${ }^{19}$ Its incidence has been reported to be of approximately $4-14 \%$ of the population. ${ }^{20}$ In the present radiological study, it was of $7.76 \%$. The three subtypes of pancreas divisum were identified in the present MRCP study, which is similar to the findings of Adibelli et al ${ }^{7}$ and Kamisawa and Okamoto. ${ }^{21}$ In the present cadaveric study, ansa pancreatica (type $\mathrm{V}$ ) was observed in one cadaveric specimen, but not radiologically. It was reported radiologically in the MRCP (1.2\%) by Adibelli et al. $^{7}$ Hayashi et $\mathrm{al}^{22}$ found that it has a significant association with recurrent acute pancreatitis.

In the present radiological study, a type-VI variant was noted where the MPD and APD open into the major and minor duodenal papillae respectively, with the APD having no communication with the MPD. Such a variation has been reported earlier. ${ }^{23}$ This has been designated as typeVI, and was observed in $7.76 \%$ of the cases.

The studies reported different incidences of the APD. Dawson and Langman ${ }^{2}$ reported it as $92 \%$ in the North American population; Sunjida Shahriah et al, ${ }^{3}$ as $27.69 \%$ in Bangladesh; and Wilasrusmee and Pongchaicherks, ${ }^{24}$ as $57.26 \%$ in Thailand. In the present cadaveric study, the incidence was of $66.67 \%$, and it was of $41.74 \%$ in the radiological study. As for the communication of the APD with the MPD, Dawson and Langman ${ }^{2}$ reported a rate of $77.7 \%$, and Sunjida Shahriah et al, ${ }^{3}$ a rate of $16.93 \%$. Double, triple and quadruple communications have been reported in another study. ${ }^{3}$ In the present study, no such additional communications were noted.

The patency of the APD was also studied by Dawson and Langman $^{2}$ in 20 fetal specimens of gestational age ranging from 13-32 weeks, and in 20 infants up to the age of 4.5 years. The APD was present and patent in most of the specimens (95\%). It has been shown by Dawson and Langman ${ }^{2}$ that obliteration of the APD and minor papilla rarely occurs during fetal life, which is not in line with the present study, in which the accessory duct was absent in all of the five fetal pancreas specimens, and the minor duodenal papilla was present in fetuses closer to term.

The long extraduodenal pancreatobiliary common channel has been considered a predisposing factor for gall stones and pancreatitis. ${ }^{2}$ Dawson and Langman ${ }^{2}$ reported an incidence of $26(52 \%)$ male and 21 (46.6\%) female cases of common channel with more than $3 \mathrm{~mm}$ in length between the Wirsung duct and the common bile duct. In the present study, this was observed in 2 cadaveric specimens (13.33\%), with a mean length of $5 \mathrm{~mm}$.

In conclusion, the MPD was observed in every case, and had a predominantly downward course. The most common pattern of the ductal system was type III. The present study shows that there are different anatomical types of pancreatic ductal system, which will be helpful for the hepatopancreatobiliary surgeons and during other procedures, like the ERCP.

\section{Ethical Statement}

The study was approved by the Institutional Review Board, Christian Medical College, Vellore, Tamil Nadu, India.

\section{Financial Support}

The study was funded by the Fluid Research Grant, Institutional Review Board, Christian Medical College, Vellore, Tamil Nadu, India.

\section{Conflicts of Interest}

The authors have none to declare.

\section{Acknowledgments}

The authors would like to thank the Fluid Research Committee, Christian Medical College, for funding this project. We would also like to thank our staff member, Mr. Rajkumar (artist), for his help in drawing the schematic diagram. We would also like to gratefully acknowledge those who donated their bodies for medical research and this study, as well as their families.

\section{References}

1 Bang S, Suh JH, Park BK, Park SW, Song SY, Chung JB. The relationship of anatomic variation of pancreatic ductal system and pancreaticobiliary diseases. Yonsei Med J 2006;47(02):243-248

2 Dawson W, Langman J. An anatomical-radiological study on the pancreatic duct pattern in man. Anat Rec 1961;139(01):59-68

3 Sunjida Shahriah, Mohammad Nurunnabi AS, Johora F, Siddiqua D, Ara S. Cadaveric Study of The Anatomical Variations of The Accessory Pancreatic Duct. J Bangladesh Soc Physiol 2014;9(02):83-88

4 Prasanna LC, Rajagopal KV, Thomas HR, Bhat KM. Accessory pancreatic duct patterns and their clinical implications. JClin Diagn Res 2015;9(03):AC05-AC07

5 Mortelé KJ, Rocha TC, Streeter JL, Taylor AJ. Multimodality imaging of pancreatic and biliary congenital anomalies. Radiographics 2006;26(03):715-731

6 Pavone P, Panebianco V, Laghi A, et al. [Cholangiopancreatography with magnetic resonance in the assessment of pancreatic ducts]. Radiol Med (Torino) 1997;94(1-2):61-67

7 Adibelli ZH, Adatepe M, Imamoglu C, Esen OS, Erkan N, Yildirim M. Anatomic variations of the pancreatic duct and their relevance with the Cambridge classification system: MRCP findings of 1158 consecutive patients. Radiol Oncol 2016;50(04):370-377

8 Türkvatan A, Erden A, Türkoğlu MA, Yener Ö. Congenital variants and anomalies of the pancreas and pancreatic duct: imaging by magnetic resonance cholangiopancreaticography and multidetector computed tomography. Korean J Radiol 2013;14(06): 905-913

9 Moore KL, Persaud TVN, Torchia MG. The developing human: clinically oriented embryology. 9th Ed. Philadelphia, PA: Saunders/Elsevier; 2013:540 
10 Sadler TW. Langman's Medical embryology. 8th Ed. Philadelphia, PA: Lippincott Williams \& Wilkins; 2000:306

11 Shu J, Zhang XM, Zeng N. Normal pancreatic duct: evaluation with MR cholangiopancreatography. Chinese Journal of Medical Imaging Technology. 2006;4:2004-2006

12 Ara S, Shahriah S, Begum S. The length of main pancreatic duct in Bangladeshi cadaver at different age groups. Mymensingh Med J 2011;20(02):298-302

13 Govindraj N, Shabna C. Variations in the duct system of pancreas: a cadaveric study. Int J Anat Res. 2017;5(3.1):4136-4143

14 Kang JK, Chung JB, Moon YM, Choi HJ. The normal endoscopic pancreatogram in Koreans. Korean J Intern Med 1989;4(01):74-79

15 Kochhar R, Goenka MK, Nagi B, Aggarwal R, Singh K. Normal pancreatic duct morphology in a north Indian population. Trop Gastroenterol 1996;17(04):223-225

16 Sahni D, Jit I, Harjeet. . Gross anatomy of the pancreatic ducts in north Indians. Trop Gastroenterol 2001;22(04):197-201

17 Bülow R, Simon P, Thiel R, et al. Anatomic variants of the pancreatic duct and their clinical relevance: an MR-guided study in the general population. Eur Radiol 2014;24(12):3142-3149
18 Dimitriou I, Katsourakis A, Nikolaidou E, Noussios G. The Main Anatomical Variations of the Pancreatic Duct System: Review of the Literature and Its Importance in Surgical Practice. JClin Med Res 2018;10(05):370-375

19 DiMagno MJ, Wamsteker E-J. Pancreas divisum. Curr Gastroenterol Rep 2011;13(02):150-156

20 Kuzel AR, Lodhi MU, Rahim M. Pancreatic Divisum: An Unusual Cause of Chronic Pancreatitis in a Young Patient. Cureus 2017;9 (11):e1856

21 Kamisawa T, Okamoto A. Pancreatographic investigation of pancreatic duct system and pancreaticobiliary malformation. J Anat 2008; 212(02):125-134

22 Hayashi TY, Gonoi W, Yoshikawa T, Hayashi N, Ohtomo K. Ansa pancreatica as a predisposing factor for recurrent acute pancreatitis. World J Gastroenterol 2016;22(40):8940-8948

23 Barkay O, Fogel EL, Watkins JL, McHenry L, Lehman GA, Sherman S. Endoscopic retrograde pancreatography. Clin Gastroenterol Hepatol 2009;7(09):931-943

24 Wilasrusmee C, Pongchairerks P. Pancreaticobiliary ductal anatomy in Thai people. JHepatobiliary Pancreat Surg 1999;6(01):79-85 